\title{
Combined Epidermal-Follicular Mucinous Nevus: Dermoscopic Appearance
}

\author{
Arturo Robles-Tenorio ${ }^{1}$, Francisco Javier Salazar-Torres ${ }^{1}$
}

1 Dermatology Institute of Jalisco, “Dr. José Barba Rubio”, Zapopan, México

Citation: Robles-Tenorio A, Salazar-Torres FJ. Combined epidermal-follicular mucinous nevus: dermoscopic appearance. Dermatol Pract Concept. 2022;12(1):e2022043. DOI: https://doi.org/10.5826/dpc.1201a43

Accepted: July 17, 2021; Published: January 2022

Copyright: (2022 Robles-Tenorio and Salazar-Torres. This is an open-access article distributed under the terms of the Creative Commons Attribution-NonCommercial License (BY-NC-4.0), https://creativecommons.org/licenses/by-nc/4.0/, which permits unrestricted noncommercial use, distribution, and reproduction in any medium, provided the original authors and source are credited.

Funding: None.

Competing interests: None.

Authorship: All authors have contributed significantly to this publication.

Corresponding author: Robles-Tenorio, MD, MSc, Dermatology Institute of Jalisco, “Dr. José Barba Rubio”, Zapopan, México.

E-mail: arturo.robten@gmail.com

\section{Case Presentation}

A 17-year-old Hispanic male presented with long-standing asymptomatic papules grouped as an irregular, brown, $10 \mathrm{~cm} \times 6 \mathrm{~cm} \times 0.2 \mathrm{~cm}$ plaque over the right aspect of the neck (Figure 1A). Perifollicular hypopigmentation and geometric brown structures were observed on dermoscopy (Figure 1B). Epidermal hyperkeratosis, acanthosis, papillomatosis, as well as abundant mucin deposits around the hair follicles were noted on histopathology, compatible with combined epidermal-follicular mucinous nevus $(\mathrm{MN})$.

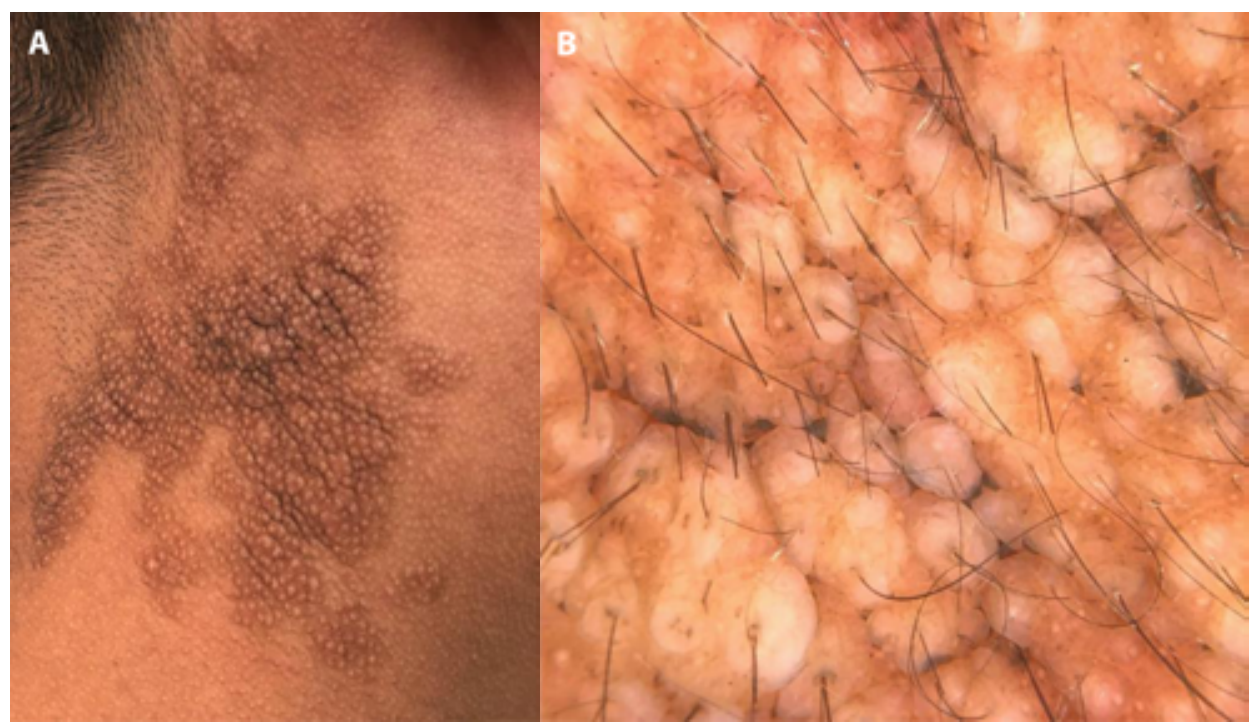

Figure 1. Combined epidermal-follicular mucinous nevus. (A) Clinical appearance. (B) Perifollicular hypopigmentation and pigmented geometric structures around the papules can be observed on dermoscopy. 


\section{Teaching Point}

There are less than 30 reports of $\mathrm{MN}$ in the literature [1]. Histopathology is essential for the diagnosis, wherein mucin deposits along the superficial dermis are present. The combined epidermal subtype also exhibits hyperkeratosis, acanthosis, and rete ridges elongation. Perifollicular mucinous involvement has only been described in one case, yet epidermal changes were subtle [2]. In contrast, we observed epidermal changes and perifollicular mucin deposits, which correlated with perifollicular hypopigmentation observed in dermoscopy. The dermoscopic appearance of MN has not been previously documented.
Informed consent: Informed consent for publication of clinical details and clinical images was obtained from the patient.

\section{References}

1. Lepage W, Frouin É, Junca A, et al. Mucinous nevus of late onset. Ann Dermatol Venereol. 2016;143(8):547-553. DOI: 10.1016/ j.annder.2016.03.017. PMID: 27197785.

2. Oiso N, Kimura M, Kawada A. Follicular mucinous nevus: a possible new variant of mucinous nevus. J Am Acad Dermatol. 2014;71(4):e141-e1422. DOI: 10.1016/j.jaad.2014.04.065. PMID: 25219735 